\title{
Using a Socio-Cultural Framework to Understand Leadership Structures Amongst the Urban Poor
}

\author{
Amy Richmond ${ }^{1}$, Richard Wolfel ${ }^{1}$, Karen Walsh ${ }^{2}$ \\ ${ }^{1}$ Department of Geography and Environmental Engineering, United States Military Academy, West Point, USA \\ ${ }^{2}$ GROW Mennonite Economic Development Associates (MEDA), Tamale, Ghana
}

Email address:

amy.richmond@westpoint.edu (A. Richmond), richard.wolfel@westpoint.edu (R. Wolfel), kayranwalsh@gmail.com (K. Walsh)

To cite this article:

Amy Richmond, Richard Wolfel, Karen Walsh. Using a Socio-Cultural Framework to Understand Leadership Structures Amongst the Urban Poor. Urban and Regional Planning. Vol. 4, No. 3, 2019, pp. 79-90. doi: 10.11648/j.urp.20190403.11

Received: May 30, 2019; Accepted: July 10, 2019; Published: July 24, 2019

\begin{abstract}
Informal settlements have been the most pervasive form of new urban development over the past half century and the gap between the rich and poor has never been wider. In this paper we determine the characteristics that are critical to understanding leadership structures in deprived regions within dense urban areas. In doing so we establish the key characteristics that contribute to urban poverty and introduce a conceptual model that can be applied to any city and contributes to an understanding of the socio-cultural characteristics of leadership structures in a slum. The framework we use in this paper to understand slum leadership structures is initially applied to Accra and Delhi. Urban poverty is frequently discussed either in terms of the developing or developed world, therefore we also apply the same framework to a disadvantaged community in the United States. This highlights that although the approaches to studying urban poor are often separate and distinct between the Global South and Global North, we believe using a similar framework can emphasize similarities and differences that might contribute to policy that is more effective in both locations. All of our discussed case studies highlight the importance of effective informal local leadership structures that communicate well with a transparent formal city government. Partnerships between all levels of leadership are paramount to successful city planning that focuses simultaneously on economic development and social equity. We expect this research will contribute to a more holistic perspective of how leadership structures within informal regions are related to the city as a whole.
\end{abstract}

Keywords: Leadership Structures, Informality, Dense Urban Areas, Accra, Delhi

\section{Introduction}

Currently half of the global population lives in urban areas. As this number increases, the population living in impoverished and deprived areas will also rise. These regions, commonly referred to as slums, housed 29.7 percent of the world's urban population in 2014 [1]. In the Global South this number was closer to 43 percent. In sub-Saharan Africa where over 25 of the world's 100 fastest growing cities are, the number of urban dwellers living in slums is over 50 percent [1]. A similar story can be told in Delhi, India, where the urban center is growing rapidly and the number of slum dwellers is significant. (Mahapatra, 2012, Kaiser, 2017) The rapid rise of people living in urban poverty presents itself as a considerable global challenge [1]. Informal settlements have been the most pervasive form of new urban development over the past half century, and the gap between the rich and poor has never been wider [2]. These settlements are economic powerhouses; for example Dharvai, a slum in India, has a GDP of somewhere between 650 million and 1 billion US dollars [3]. As such, they are destinations for migrants, which is one of the primary reasons for their continued growth. Rapidly growing cities are faced with continued sprawl, increasing poverty, inequality, and crime. The vision set out in the 2030 Agenda for Sustainable Development calls for cities that are: environmentally sustainable, resilient, socially inclusive, safe and violence free (UN-Habitat, 2016). In order to achieve this goal a deeper understanding of urban poverty is needed.

Despite the persistence of slums, leadership within slums and how the external government and local leaders interact is not well understood. Although global decentralization in governance has become an institutional phenomenon in most countries, in the developing world, top tiers of government 
are disconnected from local governance [1]. Effective urban planning is critical to providing adequate infrastructure and basic services, which are necessary to reduce urban poverty. Successful urban planning must involve bottom-up approaches; however, this is difficult to find in developing countries. One problem is that the legal system in urban areas does not represent the realities of the socio-economic processes that it is regulating. Too often the procedures that are required for urban planning are disconnected from the local population and consequently the desired outcomes are not achieved. As stated in the 2016 UN Habitat report [1] "conventional urban planning has proven singularly ineffective and often complicit in inequality." Urban legislation is necessary because it sets guidelines for access to land, infrastructure, housing, and basic services. It also can promote livelihoods and set the conditions for sustainable and equitable growth. While urban legislation exists in some areas, it is often co-opted, circumvented or completely ignored in the name of urban development. Understanding community governance and leadership positions is paramount to involving the community in urban planning [4].

In this paper we determine the characteristics that are critical in understanding leadership structures in deprived regions within dense urban areas. In doing so we establish the key characteristics that contribute to urban poverty, and how leadership structures are organized within the informal nature of the slum. We expect this research will contribute to a more holistic perspective of how leadership structures within informal regions are related to the city as a whole.

We introduce a conceptual model that can be applied to any city and contributes to an understanding of the sociocultural characteristics of leadership structures in a slum. Most research on slums has been ethnographic. As Jha et al. [5] state: "we know more about specific aspects of life in specific slums than the general dynamics of the internal and external governance processes that underpin their creation and maintenance." Cities are more complex than rural communities and new frameworks are needed to understand the urban poor. The framework we use in this paper to understand slum leadership structures is initially applied to Accra and Dehli. Because urban poverty so frequently is discussed either in terms of the developing or developed world, we then apply the same framework to a disadvantaged community in the United States. We do this to highlight that, although the approaches to studying urban poor are often separate and distinct between the developed and developing world, we believe using a similar framework can emphasize similarities and differences that might contribute to policy that is more effective in both locations.

\section{Informality}

The terms informal region and slum are used interchangeably in this paper $[6,7]$. We use the UN definition of a slum, which is a "contiguous settlement where the inhabitants are characterized as having inadequate housing and lack of basic services a slum is often not recognized and addressed by public authorities as an integral part of the city" $[9$, p. 10]. The UN describes a slum household as a group of individuals living under the same roof lacking one or more of the following conditions $[1,8]$ :

a) Access to improved water.

b) Access to improved sanitation.

c) Sufficient-living area.

d) Durability of housing.

e) Security of tenure.

Often, all five of these factors are present and in subSaharan Africa, 80 percent of slum households have 2 or more of these depravities. Slums are heterogeneous and suffer from various degrees of depravity [9].

Mahabir [10] suggest that most work on slums focuses on 1 of 3 lines of effort: 1) socio-economic and policy, 2) physical characteristics, and 3) modeling approaches using cellular data and agent-based models. Smit et al. [11] also conclude that there are certain communalities in the way that slums are researched. They suggest that slums are generally defined and analyzed along various dimensions including: 1) physical characteristics, 2) social characteristics, and 3) legal characteristics related to land ownerships and adhering to planning regulations. As a consequence, the conventional categorization of slums fluctuates between formal and informal, legal and illegal, planned and unplanned [11].

In order to grapple with the complexity of a slum one has to consider both the social and physical. Slum contextualization includes studying them as a form of human settlement, understanding their impact, and identifying the various factors relating to their continued growth and persistence [10]. Roy et al. [12] identify the following key factors that influence the emergence, growth, and persistence of slums: Population dynamics, economic growth, housing market dynamics, informal economy, local topography, street pattern, and the politics of slums. Using the example of Mumbai, Bardhan et al. [13], argue that the housing crisis and slum growth continues to be a major concern in proliferating the growth of slums. As is frequently the case, top-down approaches of slum improvement policy create a vacuum where the interests of the stake holders get lost. Often the policies reflect the political scenario rather than the real interests of slum dwellers. Lack of communication between policy makers and slum dwellers commonly cause the poor conditions in the slums to be perpetuated. In general, there is a disconnect between policy makers and the actual residents of slums, which makes a nuanced definition of a slum difficult. Once the context of a slum is understood it can lead to a conceptualization of slums where the focus is on the challenge of deriving an operational definition, which will contribute to identifying what data are necessary and how to monitor and analyze the challenges associated with slums [10].

Existing development data and inquiry tends to have a 'rural bias,' consequently little quantitative evidence is available either on the strategies of network formation or on the actual political networks of the urban poor [5]. In defining a slum, we must move beyond classifications based 
on deprivation, or as poor neighborhoods with low quality housing [11] to a definition that intricately connects it to larger socio-ecological systems. Any discussion of improving the welfare of slum residents has to involve this holistic approach. Ultimately, this will contribute to slum upgrading projects and improving the welfare of slum residents.

Dovey [2] sums up the importance of informality by stating:

"Informal controls are imposed over informal practices: informal fines, fees and bribes are paid, votes are bought, blind eyes are turned. Informal houses, shops and factories are built and inhabited by informal residents and staff. Informal land tenure and home ownership systems evolve, informal rents are paid, informal electricity and water is tapped. Informal governance operates within the framework of formal governance."

Understanding the informal leadership structures and how slums are governed is critical to not only understanding informal communities but also to developing an understanding of the best practices for implementing effective urban planning.

\section{Leadership}

Governance in slums tends to span the spectrum from traditional village institutions that have been adapted to the urban environment and new leadership structures that have emerged in the slum [5]. Leadership structures are often classified as informal leadership; however, it is not necessarily a dichotomy, but rather a continuum between informal and formal. The distinction between formal and informal is not clear and many have argued that viewing informality and formal as separate is not productive and instead the focus should be on the relationship between the two [14-16]. Myers [6] reasons that a modern city may exhibit informality to such an extent that it is an informal city. Thus, the separation of informal and formal becomes impossible as the two grow inseparably. Informal practices and settlements are combined with an informal economy and informal politics [2]. The complexity of this urban space cannot be overstated. Informality compliments the formal economy and forms numerous forward, backward, and ancillary linkages in almost all urban elements [7].

Leadership roles that focus on development work are prevalent within slums. Generally, these leaders act as an interface between the community and state development initiatives by petitioning for services. Examples include increased water access points, paved roads, and waste collection. These committees are becoming more relevant because international development agencies and researchers are stressing that local participation is critical to the success of slum improvement projects [18]. Another key function for leadership roles within a slum is to serve as intermediaries to mitigate the risks associated with living in a slum [5]. Risks include those associated with eviction, threats because of uncertain land tenure, as well as environmental disasters such as flooding and landslides, which are prevalent in slums because they tend to be built on marginal land. Srivastava [19] classifies slum leadership into four distinct types: 1) leaders who help people find vacant land and have connections with the formal local leaders; 2) leaders focused on development and on the interface between the community and formal local leaders petitioning for slums basic urban services; 3) Leaders focused on creating a voting bank. Slum dwellers represent a huge number of votes, which is why local elected officials use slum leaders to influence how the community votes; and 4) those leaders who try to protect slum dwellers from displacement. We also argue for a fifth classification representing slum leaders who take the form of illicit and organized crime groups.

\section{Methods and Conceptual Framework}

The conceptual framework we use in this paper is based on Binder's [20] approach to political development and adapted in Wolfel, Richmond, \& Grazaitis [21]. Binder [20] identifies five categories of political development, and later scholars including LaPalombara [22] and Fierman [23], added a sixth category known as allocation. These six categories, or networks, are discussed in detail in [21] and summarized below. These categories influence the development and functioning of dense urban areas from the socio-cultural perspective and in turn influence leadership structures within the city. While other networks are also important to understanding cities and leadership structures, we focus on the socio-cultural factors due to their complexity. The six categories all provide insight into urban development and work to organize the vast complexity that influences urbanization. In this paper we use these categories to address leadership structures found in impoverished regions of the city.

(1) Production Networks: refers to the physical production of material goods. In dense urban areas, labor (both skilled and unskilled) can be divided into two categories, formal and informal, however the informal and formal sector of cities are often so intertwined that separating them is futile. The formal sector of the economy is regulated by the government, through laws or taxes. Traditionally, informal activities are the dominant forms of employment among recent immigrants and consequently in slum settlements and hence are governed by informal leadership structures.

(2) Allocation Networks: refers to the way in which goods are distributed through society. In dense urban areas, there are many allocated goods including, land, food, water, medicine, infrastructure systems, among others. Allocation is closely related to legitimacy as insurgencies tend to flourish in regions where people have issues getting basic needs. Of the five leadership structures mentioned above all are involved with the allocation of resources.

(3) Identity Networks: Group membership is at the base of identity. In dense urban areas, identity groups tend to live in organized communities in specific regions of the 
city. Networks of national identity and identity in general illuminate many key issues in dense urban areas. The creation and perpetuation of migrant communities is a key example where identity influences the organization of cities. How inclusive local leadership structures are, both formal and informal, will help determine their effectiveness at reducing local poverty.

(4) Legitimacy Networks: If a population believes that the government is legitimate they are likely to follow the laws of society. At the most basic level, legitimacy is forged when a government provides for the basic needs of its population. When those needs are not provided for then the population will look for other leaders. In informal communities these leadership roles fall into the categories of leaders mentioned above. In a dense urban environment, slums are an important incubator of insurgencies because basic needs and the security of the population are often not met by the local government, consequently a legitimacy gaps evolves.

(5) Participation Networks: Participation can run the full spectrum from traditional methods of participation that includes voting to violent actions against the government, including protests, riots or insurgencies. In many dense urban areas, the traditional paths of political participation can be severely restricted. As a result, people tend to find alternative methods of participation. One of the most common alternative methods of participation is joining and participating in social movements. These movements can focus on local issues, or use local issues to tie into larger, international movements. Local leadership structures will act as organizers of these movements. Any of the five identified leadership categories can play this role. In slums, a key social movement would be protesting against eviction.

(6) Penetration Networks: these networks refer to how much effective control the government exercises. In a dense urban region, or any other region for that matter, the built environment is a key marker of political penetration. The effectiveness of a government's ability to promote its message, history and heroes is seen in the buildings, street names and monuments of a region. The location and condition (well maintained and free of vandalism) demonstrates how well the government's influence penetrates a region. Government penetration into informal urban areas is often limited, unless the government decides to go to the extreme measure of "clearing" the slum. In slum communities it is the informal leadership that has the most control.

These six elements function differently depending on the level of integration the city has. Highly integrated cities tend to be more formalized, with effective government control over most aspects of the city. At the other extreme, loosely integrated cities tend to have weak government structures, with high degrees of informality. As other variables within each of Binder's factors are added to the model, for example water in allocation, it would be expected that it would follow the same trend, very organized, with high levels of governmental oversight at the highly integrated level, while very informal at the loosely integrated level [21]. All of the identified elements of our framework are not exclusive and flow and shape each other. They are multi spatial and multidisciplinary. The goal is not to be reductionist but to highlight how these elements inform leadership within an informal community.

We initially apply this framework to four slums in two countries: Ghana and India. Determining how to utilize this framework to actual case studies involved interviews with different community leaders, literature reviews, and site visits. We then used this same framework and applied it to a city in the United States, with the goal of connecting the rhetoric of slum policies in the Global South with the discussions of urban poverty in the Global North.

\section{Case Studies}

\subsection{Accra, Ghana}

Accra is the capital of Ghana. The population of Accra is estimated to be $2,439,389$ in 2018. Since 1950, the population has grown by 149,828 - a growth rate of $2.14 \%$ [24]. Approximately 54\% of the population is under the age of 24 . About $58 \%$ of the total population of Accra is living in a slum. Although physical development in Accra is governed by a Master Plan and Sector Layout plans, growth occurs faster than planning. Consequently, haphazard development and slum conditions are the outcome. Many of Accra's slums are located in flood prone areas. Their location is based on the inability of the city to deal with housing supply deficits and to provide affordable housing and community infrastructure [25]. We visited two informal communities in Accra: Nima and Old Fadama in 2017 and 2018. Nima is a densely populated community made up of predominately Muslim migrants, though a variety of ethnic groups live in the community. Old Fadama is the largest informal settlement in Accra, and in 2002 a Ghanaian High Court issued an eviction order on the grounds of illegality. Civil organizations intervened and started a dialogue that led the community to be amenable to proper relocation in 2008 [26]. This however has not occurred, and instead, 17 years of eviction threats and community resistance have ensued. The community is located along a heavily polluted lagoon, the clean-up of which was the initial motivator for the plan to demolish of Old Fadama.

\section{Applied framework to Accra, Ghana}

(1) Production: the majority of slum residents engage in informal labor. Both communities, but particularly Old Fadama are entry points of unskilled rural-urban migrants into Accra. The population of Old Fadama has been increasing rapidly because of an unprecedented rate of migration of young people, mostly girls between the ages of 10 and 30 years of age, who are in search of economic opportunities [25]. Informal labor 
contributes to the functioning and economy of the city by providing services to the community, such as collecting urban waste and recycling, as economic actors, as political actors, and as drivers of social change [26]. Street hawking is another form of informal labor and has been met by an aggressive response by city authorities who do not want hawkers in public urban space [27].

(2) Allocation: the majority of the five above identified slum leadership roles fall into allocating resources. Arguably the two most important resources in Accra's slum communities are water and land. There are very few improved water sources in either community and both Nima and Old Fadama face challenges of water availability and affordability. Also, there are limited adequate sanitation facilities and most garbage and sewage ends up in open drains. Water is more expensive for the people in slums than the rest of the city and far higher than the cost in the rural areas. This is particularly true in Old Fadama where water is significantly more expensive than elsewhere. Water is managed by private parties and is supplied by Ghana Water supply. In Old Fadama thirty-five liters of water costs 1 Ghana Cedi, which is approximately 4 times the amount of what it costs in Nima.

Land tenure is another resource in these communities and as a result land-owners have considerable power. Ghana's land is governed by a pluralistic legal system in which customary and statutory systems overlap [28]. Statutory systems involve written, codified rules dictating who has access and for what purpose; customary systems are more informal, based on community understanding and tradition. Customary law considers property as a family asset to be administered by the family head, who is usually a man. Access to land may be through inheritance, pleading, marriage, sharecropping or renting [29]. Land tenure is arguably the largest driver of vulnerability and conflict in informal communities. Chiefs are members of the ruling families who have been in power for generations. Land can be leased with 99-year leases and these leases can be sold. It is impossible to keep track of who owns the land or when the leases are over their 99 years. Land, and even space in leased rooms, is passed down from generation to generation. Land disputes are common and take up a considerable amount of Chiefs and courts time. Government owned land generally houses the most vulnerable people because the government will not provide services because they do not want people occupying their land. In Old Fadama the most basic services do not exist here and the overall health of the population is dire. Sanitation is extremely poor and garbage and sewage is everywhere. Flying toilets (human feces put into a plastic bag and tossed) and open defecation is the norm [30]. The government frequently threatens eviction, which results in the residents and the government being reluctant to invest in improving their living situation. In contrast, in Nima where the fear of eviction is not present due to the fact that the land is owned by Chiefs, the residents are improving their houses from clay bricks, to concrete cinder blocks, and even in rare cases, a dwelling with a second-floor.

(3) Identity: Neighborhoods in Accra tend to be organized by ties to ethnicity, tribalism, and/or historical development [31]. Strong ethnic residential segregation is generally more balanced in Accra than in other large cities [32]. The exception to this would be the Ga ethnicity, located along the coastal areas of Accra [33]. Social networks in slums are important because they play a role in how vital resources, such as water, are accessed and shared [34]. In Accra, these networks consist primarily of family and neighbors. Neighbors, which are often family members, live in close proximity and frequently will share sanitation facilities and collect water from them same sites.

The underlying cause of segregation in Accra is the socioeconomic circumstances of the migrant and indigenous populations [32]. This socioeconomic segregation is also highlighted by studies that focus on health. Aggrey-korsah \& Oppong [35] for example, show health vulnerability within Nima is based on where one lives within the slum. It would be inaccurate to classify the slum residents as homogeneously vulnerable $[31,35]$. Without equal access to housing and land, such segregation will likely continue. This results in a socioeconomic continuum where it is not uncommon to find professions associated with the upper and middle classes such as doctors and lawyers are living in slums [36]. Local leadership structures frequently account for ethnic diversity in their organization.

(4) Legitimacy: Both Nima and Old Fadama are generally indicative of a common pattern in slums, where local institutions have the power to govern but do not have the legal backing to exercise authority. The statutory institutions that have the formal authority to rule do not necessarily have the power to do so [37]. There are exceptions. For example, the Mothers Club in Nima has become the defacto legitimate representatives in the community and to the government of Ghana. The club might not hold legal status, but the leadership is able to negotiate for services on behalf of the community. Conceivably this is where a more formal and longer standing slum might transition between total informal to formal.

(5) Participation: Governance is complicated in a variety of ways. Ghana is governed both by elected government officials (formal) and Chiefs (informal). Corruption is present in both forms of government and many rules are not enforced. Without enforcement of laws and water rules, the Ghanaians will find little change to their issues surrounding water and sewage dumping. The majority of governance in slums is informal where Chiefs are the primary community leaders. There are, however, also elected officials that are part of Ghana's official government. Often elected officials attempt to "twist the arm" of Chiefs to get votes from their followers. There can be multiple Chiefs per community leading to significant tensions 
among them. These Chiefs are often of different ethnicities and religions, for example, Christian and Muslims.

Within the slum, community boards are elected to govern resources such as water. Water-boards, for example, decide where to build the boreholes or taps and how to manage the profits. Other informal governance groups, such as women's groups, can wield significant influence. In Nima there are several groups that can be considered leadership groups. For example, the elected water board consists of 11 members from different ethnic groups including four women. The Mothers Club is also a significant source of this sort of informal leadership. Its primary function is to organize women in the community to improve livelihood, create economic opportunities and provide funding for primary education. Leadership groups work well together despite different ethnicities and religions. Other leaders in the communities are doctors and teachers. Criminal networks also immerge from within the community and can yield significant power. This is particularly apparent in the most vulnerable areas.

In Old Fadama there is the Peoples Dialogue on Human Settlements (PD), whose principle role is to act as a liaison between the residents and the government. They also contributed to the establishment of the Old Fadama Development Association (OFADA) in 2004 [37]. OFDA is an example of community governance that oversees many of the activities in Old Fadama. As Stacey \& Lund [37] describe:

"They look out for new constructions that block pathways; they call on emergent businesses; they ensure broader access roads are kept clear of containers and vehicles; they caution young people riding motorbikes carelessly; if they spot leaky pipes they contact volunteer plumbers; they identify fire hazards and endeavor to 'keep the rubbish moving' to minimize problems with vermin; they look in on recurring domestic disputes and shoo children to school; they follow up on complaints of theft and damage to property, and pursue disagreements over rental payments; they give newcomers advice on building; after heavy rain they inspect low-lying areas for flooding; they rally communal labor to clear blocked waterways and ensure unsafe buildings are demolished after outbreaks of fire; they also organize the collection of contributions to cover medical bills, funeral expenses and support to families when a deceased person must be returned to what is often a remote northern village; and in some instances they cover bail money when it cannot be raised by relatives."

(6) Penetration: In the two slums that we visited in Accra the level of government penetration varied significantly. Generally, the formal government did not have much influence in the community because services that are provided by the government (roads, water, waste collection) are sparse if not nonexistent. The exception to this would be the government's influence by threatening the community with eviction, as is the case in Old Fadama. Alternatively, politicians canvas for votes in the community by promising not to raze the slum. In the Nima Slum, where eviction is not a threat, the government did build a paved road into the community which has improved accessibility significantly.

\subsection{Delhi, India}

Delhi is the capital of India with a population of approximately 29 million in 2018, making it one of the largest cities in the world (indiapopulation2018. in). The population grows by approximately 1 million people per year. Estimates of the percent of the population living in slums varies widely from $50 \%$ of the population (Mahapatra, 2012) to about $10 \%$ of the population (Kaiser, 2017). This wide variation shows the unregulated and informal nature of slum development in Delhi.

As with Accra, growth occurs faster than planning. The Delhi Development Authority (DDA) is a powerful agency that governs urban development in Delhi. The DDA has been at the vanguard for the creation a new "world class" Delhi [38, 39]. According to Ghertner [39] this is a vision based on aesthetics as the DDA relies on appearance as the basis of legality. The result of this shift to aesthetics has been a haphazard policy of slum clearance, with a logic grounded in visibility and functionality of a specific site. Areas closer to the urban center, for example, that are more likely to be viewed by tourists, have been target for slum clearance.

The analysis of Delhi utilizes observations from two slum neighborhoods, Kathputli Colony and Sanjay Colony. Sanjay is a small slum built on 25 acres in the Okhla Phase 2 region of Delhi. This is an industrial region, with a wide diversity of economic activities. The diverse population of approximately 50,000 is made up of primarily immigrants from surrounding regions of India. Due to its location in an industrial neighborhood, and the ability to provide informal labor to support industrial development, Sanjay is at little risk for destruction, and has even seen some development, especially from the Delhi Water Board.

Kathputli Colony, on the other hand, is located towards the center of Delhi in the Shadipur region of Delhi. It is made up of approximately 2,800 families, mostly from the Rajistan region. The colony did have some industry, but the focus is on street performers, mainly puppeteers. With its proximity to the center of Delhi and the lack of connection to other economic activities in Delhi, the colony has been the target of development plans since 2010. In late 2017, the slum was bulldozed and the population relocated.

Applied framework to Delhi, India

(1) Production: Both neighborhoods engage predominately in informal labor. In Kathputli, this consists of puppet shows for tourists. In Sanjay, textile recycling was the major informal employment activity. Formal activities were visible in each neighborhood, as well, with small scale clothing manufacturing dominating in both colonies. Stores and doctors had locations in both neighborhoods to serve the colonies. Traditional forms of informality, street begging and petty theft, were 
virtually nonexistent in both neighborhoods.

(2) Allocation: As in Accra, water and land are the two most important resources in the slum and many leadership roles focused on these two resources. In Sanjay, water is either provided through internal plumbing in the home or through water trucks, owned by the Delhi Water Board. In Kathputli, most water was provided by the Delhi Water Board from a central water tank. The existence of internal plumbing in Sanjay provides a greater sense of permanence for the citizens of the colony. The Delhi Water Board is also making significant investments in Sanjay by building a new toilet facility for the residents. Most of the leadership roles in terms of water are held by the government through the Delhi Water Board. In our experience, this is somewhat unique to Delhi, as in other Indian slums, especially Mumbai [40], water is more privatized.

Land tenure is the most critical issue facing the residents of Sanjay. In Kathputli, a lack of land ownership was the mechanism by which the Delhi Development Authority was able to remove the citizens and destroy the neighborhood. In both neighborhoods, land is owned by the state. In Sanjay, houses are owned by individuals. About $30 \%$ of the residents own their own house and the rest rent the houses from a private owner. The individual ownership of houses creates more stability in Sanjay, an attribute visible in the more permanent nature of the structures. Houses in Sanjay typically have multiple floors, some have internal plumbing and all have electricity. In Kathputli, since the land tenure system was more tenuous, housing stock was of a lower quality. Most houses were one story with no running water. Electricity was more improvised in Kathputli with people tapping into electric lines to access electricity.

(3) Identity: Overall, there is a strong sense of identity to the local colony, this was especially true in Kathputli. This sense of shared identity was due to a large proportion of the citizens of the colony coming from Rajistan and sharing the same tradition as street performers and puppeteers. In terms of religion, a wide diversity of religion, especially Hindu and Muslim, live in close proximity with a high level of mutual respect and tolerance. The caste system is virtually nonexistent in the slums of Delhi. Most of the citizens of both Sanjay and Kathputli share a migrant identity in that almost all citizens moved from rural to urban settings. Sports figures are identified as heroes, especially among the younger citizens.

(4) Legitimacy: There are two main trajectories that influence the legitimacy of the government in slum communities. First, Narendra Modi, Prime Minister of India, has worked hard to create an image of humility and empathy, trying to make connections to Mohandas Gandhi as part of his political discourse. Other politicians have followed along, trying to gain support of slum communities by championing causes popular to slum dwellers. In recent years, Arvind Kejriwal,
Chief Minister of Delhi, has addressed key issues from anti-corruption to food security as part of his political agenda, thus twice earning his election as Delhi's Chief Minister [41]. His grassroots activism makes him an extremely popular political figure in the slums of Delhi, as seen in discussions with residents in Sanjay Colony.

On the negative side, the lack of government involvement in slum neighborhoods has left a leadership void. In Delhi, often this void is most visible in education, housing and employment. Water, which is critical in Mumbai, is typically provided by the Delhi Water Board and is not a significant issue in the slums we visited. Nongovernment Organizations (NGOs) often step in to fill this void, especially in providing education and employment opportunities. NGOs have set up vocational schools in various slums. The NGOs also set up supplemental English language training for the citizens of the slums. When speaking to the citizens of Kathputli, they often complained about the tenuous nature of their land tenure situation. When they spoke of the plans for the new Kathputli [42], the citizens speak with a sense of frustration, inevitability and defeat. They believe the promises from the government about returning to Kathputli are false. They do not think they will be able to afford the new apartments.

(5) Participation: India has a strong democratic tradition in recent years. As a result, slum dwellers are an important block of voters for politicians at all levels, from the local wards to the federal government. There are formal and informal avenues of participation within the slum communities.

In terms of formal participation, ward politics are important. In Delhi, ward representatives to the city government are significant powerholders in slum communities, acting as a conduit of information for local citizens and the liaison to the city government for the local citizens. They also typically employ local citizens, typically referred to as Pradhans, to help organize and conduct rallies in the neighborhood. Since the gap (political, social, economic) between government and slum dweller is quite large, the ward politicians and their Pradhans, are often the only opportunity for individual slum dwellers to interact with the government.

In terms of informal participation, several organizations exist outside of the government that work to organize and protect the needs of local citizens. As previously mentioned, NGOs step in to fill the void when government services do not reach the local citizens of the slums. There are some examples of local community-based organizations that utilize their position as a large block of local citizens to lobby for the needs of the local slum community, especially when the slum is threatened with destruction. This is significant because individual slum dwellers typically have limited participatory opportunities, outside of voting.

(6) Penetration: Viewing the large slum population as a powerful voting bloc, political leaders have worked hard to push their messages into slum regions. Modi launched the Pradhan Mantri Ujjwala Yojana (PMUY) 
campaign to provide liquefied petroleum (LPG) cooking gas to all Indian households, with the account name being that of the adult woman of the household [43]. This campaign pushes several of Modi's key governing objectives: women's empowerment, protection of women and clean energy [44]. Further pushing the success of the program, the government has posted many posters touting the success of program, all over Delhi, from street corners to the airport departure concourse.

The recent slum clearance campaign can also be seen as a form of political penetration. The use of aesthetics and labeling slum neighborhoods and slum dwellers as a "nuisance" has facilitated the removal of slum colonies as part of the Delhi Development Agency's push to create a "world class city." In looking to host international events, like the Commonwealth Games, the DDA marginalized slum dwellings to locations outside of the traditional travel paths of tourists [39]. This is a powerful example of political penetration, one which has forced a large proportion of the Delhi population to relocate away from the center of the city.

\section{The Framework Applied to a North American City}

Urban poverty in the Global South is usually discussed in isolation to urban poverty in the Global North. In many ways this is understandable, because there are plenty of differences between the two locations. However, the framework we derived can potentially be applied to a North American city and perhaps by focusing on the common threads in urban poverty, lessons learned from the Global North can be applied to the Global South and vice versa. There is some argument in the literature that supports this type of endeavor. Roy [14] makes the case that there are important themes that cut across the usually separated domains of "international development" and "community development" by stating that: "On the one hand, informal spaces have been perceived as unplannable; on the other hand, there has been a series of attempts to improve and integrate such spaces. These mandates of improvement and integration bear resemblance to efforts in the American context to manage spaces of poverty". It is important to acknowledge that comparing American cities with cities in the Global South does not suggest that American cities are more advanced in poverty policies [15]. In American cities slum policy has been replaced with urban revitalization often resulting in gentrification, which more often than not, does not benefit the people originally living in the neighborhood [45]. Slum policies in the Global South have been dominated by the rhetoric layout in "Cities without slums" [8], which can be understood as the new war on poverty. [45]

Newburgh, NY

Newburgh is a relatively small city (population: 28,406) that is 60 miles north of New York city on the west bank of the Hudson River. During the $19^{\text {th }}$ Century Newburgh was a prosperous shipping, transportation, and industrial hub. Later in the $20^{\text {th }}$ Century Newburgh began to decline as manufacturing and industry moved elsewhere, and the New York State thruway bi-passed the city undermining its role as the gateway to the Hudson Valley. Under the banner of Urban Renewal, federal funding led to the razing of dozens of blocks of neglected buildings to make way for "something new." That "something new" never materialized and much of the land still remains empty today. Currently Newburgh is economically and socially depressed. It was declared the $9^{\text {th }}$ most distressed urban center in the country based on the 2010 census information [46]. Poverty effects nearly one third of the population in Newburgh.

Applied Framework to Newburgh, NY

(1) Production: Newburgh has a disproportionally large population of youth and young adults compared to national levels. This, combined with a low (63\%) high school graduation rate, leads to a significant number of unemployed or underemployed youth, making it very hard to break the cycle of poverty [46]. As of 2016, 29.7 percent of the population lived below the poverty line, which is a significantly larger proportion than in the neighboring communities and in the country as a whole. Newburgh is plagued by gang violence centered around illegal drug trafficking.

(2) Allocation: Seventy percent of Newburgh residents rent, 60 percent of these renters experience a housing cost burden (where families pay more than 30 percent of their income on housing) [47, 48]. Roughly twenty percent of Newburgh's housing stock is vacant and in poor condition. There are ongoing infrastructure and environmental issues, including water quality, street maintenance, enhancements to the Hudson River waterfront, and cleanup of former brownfield sites. Water in particular is a concern because in May 2016 the primary source for Newburgh's watershed was found to be contaminated with toxic chemicals and was closed, forcing Newburgh to purchase water from the New York City water supply [49]. Newburgh's roads are also in poor condition which limits mobility [47]. It is the city government's role to allocate these resources, however it is often local groups that advocate for better quality services.

(3) Identity: In recent years there has been growth in the Hispanic population. The Hispanic population has grown from just over one third of the total in 2000 to one half of the population in 2016. Today Newburgh's population is $49.8 \%$ Hispanic, $25.4 \%$ black, and $20.3 \%$ white [47]. Social networks play a large role in the Hispanic population of Newburgh and influence where people live and employment opportunities.

(4) Legitimacy: In 2013 Newburgh had a per capita crime rate of 6.10 , a number three times that of New York City [46]. This is an unusually high per capita crime rate for a city the size of Newburgh and there are inadequate police resources to handle the crime. However, the crime index has declined since 2013 and 
violent crime has steadily declined since 2012 [47]. The City has increased enforcement and in 2018 several large operations were conducted that resulted in multiple arrests $[50,51]$. Building code enforcements have also been on the rise.

(5) Participation: In Newburgh there is a mix of both formal government and informal government. Formal government agencies that focus on urban poverty include the City's planning department and law enforcement. Neighborhood associations, nonprofit organizations, and advocacy groups have become common in Newburgh with a focus on neighborhood revitalization. These organizations are not part of the formal Newburgh government but have had significant influence in the community. The 2018 City of Newburgh Vision Plan states that: "As the City moves forward into developing its Comprehensive Plan, representatives from many nonprofit organizations, advocacy groups, and leaders of ongoing initiatives will be key stakeholders in the completion of the Plan." [47] The government of Newburgh stresses the importance of its connection to civic organizations. The community, in a 2018 public workshop, also stressed that having an "accountable, responsive, open, and effective local government" is a critical concern [47].

(6) Penetration: Penetration by the formal government can most often be felt in terms of taxes. The existing tax structure in Newburgh disproportionately levies residential properties as a result of high vacancy rates and few commercial establishments on the tax rolls [47]. Consequently, many landlords cannot afford improvements on their homes resulting in substandard living conditions for their tenets. It is not uncommon to find dwellings that violate basic fire and safety codes.

\section{Discussion}

Arguably, applying the framework to Newburgh highlights the similarities in urban poverty between all of the mentioned case studies. Perhaps the most striking commonality is the fact that the urban poor are primarily not land owners. In Newburgh there are organizations in place that actively attempt to help the urban poor become home owners, such as Habitat for Humanity and the Newburgh Land Bank. These organizations work closely with the city government to determine which houses to rehabilitate and to obtain the necessary permits. The city encourages this rehabilitation because ultimately it will add to its tax base. Similar efforts do exist in our developing world case studies, however, the relationship between the formal government and the NGOs and community leaders who are focused on slum upgrading projects is not as apparent or as functional. Slum upgrading techniques through the use of property rights is not new and was championed by de Soto [52]. The fundamental idea is that property rights for slum dwellers would provide them with a formal asset that would allow them to get loans to start businesses, thus transitioning the informal economy to the formal. However, others argue that an emphasis on homeownership in the Global South can create additional burdens for those who are not able to qualify for a mortgage. Also, there is little evidence in practice that having a legal title makes any difference in the availability of formal finance [53]. It also encumbers minority groups and women because their rights are linked to male family members or otherwise restricted by cultural norms [54]. Another interesting concern with formal property rights is highlighted in an article about Brazil slum dwellers would make them vulnerable to gentrification, that might in turn, price these vulnerable populations out of the area, because formal titles enable people to sell their homes. The article states: "Many economists believe that formalizing property ownership will give poor residents more security and let them buy and sell their homes on the market, like anyone else. Activists say this informality protects favela residents from gentrification, as big investors aren't interested in properties lacking titles."[55] Gentrification is a lead concern in US cities, and the fear is that many strategies to improve impoverished neighborhoods might result in poor people being forced to leave because of increased rents. Eviction caused by gentrification is found to be positively associated with neighborhoods in the pre stages of gentrification, hence policies focusing on communities that have the potential to gentrify might help ameliorate displacement. [56]

Another similarity between all three cases is that there is a mix of both formal and informal governance. The five types of leadership structures identified above hold true for all case studies. For example, leadership that focuses on the allocation of resources can be observed in all locations. The Mothers' Group in Nima is focused on supplying clean drinking water to the community. In Newburgh environmental groups such as River Keeper are pushing for the clean-up of the Newburgh drinking water supply. In Delhi NGOs, including WaterAid India, have been active in slum communities trying to improve water quality and hygiene for slum residents and also organizing rallies to bring attention to water pollution, especially on the Yamuna River. Criminal networks also appear in all case studies and the ability of the formal government to curb illegal activity is difficult.

There are of course differences between all communities as well. For example, Newburgh has vacant housing stock that is in desperate need of rehabilitation, and the population of Newburgh is relatively stable. Clearly this is quite different in the other case studies where crowding and rapid population rise are a primary concern. This difference is primarily a function of the way these cities are viewed. Slums in the Global South are typically seen as areas of opportunities for employment. Newburgh however, is not considered as a location for opportunity. This perception of Newburgh might change if the city is revitalized by upgrading. Upgrading [57] can fall into three classes: 1) gentrification, 2) upgrading by veteran residents, 3) upgrading by immigrants from cities in the Global South, many of whom are skilled workers hoping to become members of the middle class. 
The point of this exercise is, again, not to attempt to generalize between the very unique set of circumstances in each of our case studies, but instead to suggest that by applying our framework there are lessons that can be learned from each of our diverse locations. Diverse community led organizations seem to be a key driver in fighting against urban poverty. A deeper investigation into these organizations will help decipher what successful traits are.

\section{Conclusion}

While there are certain characteristics that exist in all dense urban areas, the way these characteristics manifest themselves is unique from place to place. Each city will differ in the specifics, however there are general trends that contribute to understanding how cities function. Creating an organizational framework for leadership structures in deprived regions within dense urban environments helps determine the key characteristics that contribute to effective and ineffective governance. For example, Carmon [57] suggests slum policies in the U.S. since the 1930's have cause more harm than good and Murrary [58] argued that despite the increases in federal spending on social welfare between $1950-1980$, the war on poverty only managed to produce more poor and the quality of life for the poor deteriorated sharply between 1965 and 1980. How do we avoid these pitfalls in the efforts to produce cities without slums in the developing world and improve urban poverty in the developed? Although this paper does not attempt to answer those questions, by introducing the framework we can start to analyze common themes. For instance, all of our discussed case studies highlight the importance of effective informal local leadership structures that communicate well with a transparent formal city government. Partnerships between all levels of leadership are paramount to successful city planning that focuses simultaneously on economic development and social equity. There are significant lessons to be learned by not looking at urban poverty issues in the developed and developing world in a vacuum.

\section{References}

[1] UN-Habitat, "Urbanization and Development: Emerging Futures," 2016.

[2] K. Dovey, "Informal urbanism and complex adaptive assemblage," Int. Dev. Plan. Rev., vol. 34, no. 4, pp. 349-368, 2012.

[3] D. McDougall, "Waste not, want not in the $£ 700 \mathrm{~m}$ slum Environment | The Guardian," The Guardian, 2007. [Online]. Available:

https://www.theguardian.com/environment/2007/mar/04/india. recycling. [Accessed: 19-Feb-2019].

[4] A. Richmond, I. Myers, and H. Namuli, "Urban Informality and Vulnerability: A Case Study in Kampala, Uganda," Urban Sci., vol. 2, no. 1, p. 22, 2018.

[5] S. Jha, V. Rao, and M. Woolcock, "Governance in the Gullies:
Democratic Responsiveness and Leadership in Delhi's Slums," World Dev., vol. 35, no. 2, pp. 230-246, 2007.

[6] G. A. Myers, Urban environments in Africa: A critical analysis of environmental politics. Great Britain: Policy Press, 2016.

[7] A. K. Richmond, D. Malcomb, and K. Ringler, "Household vulnerability mapping in Africa's Rift Valley," Appl. Geogr., vol. 63, pp. 380-395, 2015.

[8] UN-Habitat, "THE CHALLENGE OF SLUMS," 2003.

[9] UN Habitat, "State of the World's Cities 2006/7 The Millennium Development Goals and Urban Sustainability: 30 Years of Shaping the Habitat Agenfa," London, UK, 2006.

[10] R. Mahabir, A. Crooks, A. Croitoru, and P. Agouris, "The study of slums as social and physical constructs: Challenges and emerging research opportunities," Reg. Stud. Reg. Sci., vol. 3 , no. 1 , pp. 399-419, 2016.

[11] S. Smit, J. K. Musango, Z. Kovacic, and A. C. Brent, "Conceptualising slum in an urban African context," Cities, vol. 62, pp. 107-119, Feb. 2017.

[12] D. Roy, M. H. Lees, B. Palavalli, K. Pfeffer, and M. A. P. Sloot, "The emergence of slums: A contemporary view on simulation models," Environ. Model. Softw., vol. 59, no. 2014, pp. 76-90, 2014.

[13] R. Bardhan, S. Sarkar, A. Jana, and N. R. Velaga, "Mumbai slums since independence: Evaluating the policy outcomes," Habitat Int., vol. 50, pp. 1-11, 2015.

[14] A. Roy, "Urban informality: Toward an epistemology of planning," J. Am. Plan. Assoc., vol. 71, no. 2, pp. 147-158, 2005.

[15] T. Bunnell and A. Harris, "Re-viewing informality: perspectives from urban Asia," Int. Dev. Plan. Rev., vol. 34, no. 4, pp. 339-348, 2012.

[16] J. Minnery et al., "Slum upgrading and urban governance: Case studies in three South East Asian cities," Habitat Int., vol. 39, pp. 162-169, 2013.

[17] G. Myers, Urban environments in Africa, 1st ed. Bristol University Press, 2016.

[18] A. M. Auerbach, "Neighborhood Associations and the Urban Poor: India's Slum Development Committees," World Dev., vol. 96, pp. 119-135, 2017.

[19] A. K. Srivastava, "Leaders of Slum Dwellers -A study based on slums of Jaipur city," IOSR J. Humanit. Soc. Sci., vol. 8, no. 2, pp. 18-24, 2013.

[20] L. Binder and J. La Palombara, Crises and sequences in political development. 1971.

[21] R. Wolfel, A. Richmond, and P. Grazaitis, "Seeing the Forest through the Trees: Sociocultural Factors of Dense Urban Spaces," Urban Sci., vol. 1, no. 4, p. 40, 2017.

[22] J. La Palombara, "No Title," in Crises and sequences in political development, 1971, pp. 233-282.

[23] W. Fierman, Language planning and national development: the Uzbek experience. Mouton de Gruyter, 1991.

[24] “Accra Population 2018 (Demographics, Maps, Graphs)." 
[Online]. Available: http://worldpopulationreview.com/worldcities/accra-population/. [Accessed: 15-Nov-2018].

[25] C. Amoako and D. K. B. Inkoom, "The production of flood vulnerability in Accra, Ghana: Re-thinking flooding and informal urbanisation," Urban Stud., vol. 55, no. 13, pp. 2903-2922, 2018.

[26] M. Oteng-Ababio, A. Tanle, S. T. Amoah, L. Kusi, E. A. Kosoe, and E. Bagson, “'Informal Exceptionalism?' Labour Migrants' Creative Entrepreneurship for Sustainable Livelihoods in Accra, Ghana," J. Asian Afr. Stud., 2018.

[27] T. Gillespie, "From quiet to bold encroachment: contesting dispossession in Accra's informal sector," Urban Geogr., vol. 38, no. 7, pp. 974-992, 2017.

[28] Land Links, "Ghana | LandLinks." [Online]. Available: https://www.land-links.org/country-profile/ghana/. [Accessed: 19-Feb-2019].

[29] CEDAW, "Convention on the Elimination of All Forms of Discrimination against Women Provisional agenda," 2005.

[30] Europa Source, "World Toilet Day Ghana ranked 2nd in open defecation - Pulse Ghana," pulse.com, 2015. [Online]. Available: https:/www.pulse.com.gh/ece-frontpage/worldtoilet-day-ghana-ranked-2nd-in-open-defecation/ym83fy7. [Accessed: 19-Feb-2019].

[31] A. Getis, "Analytically derived neighborhoods in a rapidly growing West African city: The case of Accra, Ghana," Habitat Int., vol. 45, no. P2, pp. 126-134, 2015.

[32] G. Owusu and S. Agyei-Mensah, "A comparative study of ethnic residential segregation in Ghana's two largest cities, Accra and Kumasi," Popul. Environ., vol. 32, pp. 332-352, 2011.

[33] J. R. Weeks, A. G. Hill, A. Getis, and D. Stow, "Ethnic residential patterns as predictors of intra-urban child mortality in Accra, Ghana," Urban Geogr., vol. 27, no. 6, pp. 526-548, 2006.

[34] E. K. Dapaah and L. M. Harris, "Framing community entitlements to water in Accra, Ghana: A complex reality," Geoforum, vol. 82, no. April, pp. 26-39, 2017.

[35] E. Aggrey-korsah and J. Oppong, "Researching Urban Slum Health in Nima, a Slum in Accra Emmanuel," in Spatial Inequalities: Health, Poverty, and Place in Accra, Ghana, vol. 110, no. May 2013, J. R. Weeks, A. G. Hill, and J. Stoler, Eds. 2013, pp. 109-124.

[36] M. M. Jankowska and R. Engstrom, "Spatial Analysis of Accra, Ghana," vol. 17, no. 4, pp. 221-235, 2013.

[37] P. Stacey and C. Lund, "In a state of slum: Governance in an informal urban settlement in Ghana," J. Mod. Afr. Stud., vol. 54, no. 4, pp. 591-615, 2016.

[38] S. Banerjee-Guha, "Neoliberalising the 'Urban': New Geographies of Power and Injustice in Indian Cities," Econ. Polit. Wkly., vol. 44, no. 22, pp. 95-107, Jun. 2017.

[39] D. A. Ghertner, Rule by aesthetics : world-class city making in Delhi. 2015.

[40] L. Weinstein, "Mumbai's Development Mafias: Globalization, Organized Crime and Land Development," Int. J. Urban Reg. Res., vol. 32, no. 1, pp. 22-39, Mar. 2008.
[41] H. Baweja, "How Arvind Kejriwal became the little, big man of Indian politics," Hindustan Times, 08-Dec-2013.

[42] Delhi Development Agency, "Kathputli Colony - DDA | Slum Rehabilitation Delhi," 2014. [Online]. Available: http://www.kathputlicolonydda.com/. [Accessed: 19-Feb2019].

[43] Ministry of Petroleum and Natural Gas, "About PM Ujjwala Yojana," 2019. [Online]. Available: http://www.pmujjwalayojana.com/about.html. [Accessed: 19Feb-2019].

[44] N. Naryanan, "Narendra Modi's Ujjwala Yojana: LPG connections has gone up but the actual use has not kept pace," 2019. [Online]. Available: https://scroll.in/article/908643/themodi-years-are-more-indians-using-cooking-gas-because-ofthe-ujjwala-scheme. [Accessed: 19-Feb-2019].

[45] Z. Kovacic, "Governing informality through representation: Examples from slum policies in Brazil and South Africa," Cities, no. January, pp. 0-1, 2018.

[46] C. Collins, J. Uwilingiyimana, and L. Fothergill, "Community conditions field study NewBurgh NY," 2013.

[47] “City of Newburgh Vision Plan 2018,” Newburgh, NY, 2018.

[48] PD\&R Edge, "Rental Burdens: Rethinking Affordability Measures | HUD USER." [Online]. Available: https://www.huduser.gov/portal/pdredge/pdr_edge_featd_artic le_092214.html. [Accessed: 19-Feb-2019].

[49] L. Sparks, "Newburgh 'giving up' on reopening primary water supply," Times Herald Record, 2018. [Online]. Available: https://www.recordonline.com/news/20180814/newburghgiving-up-on-reopening-primary-water-supply. [Accessed: 19Feb-2019].

[50] J. Howland, "16 defendants in Hudson Valley drug ring enter guilty pleas," Poughkeepsie Journal, 2018. [Online]. Available:

https://www.poughkeepsiejournal.com/story/news/local/2018/ 05/12/16-defendants-hudson-valley-drug-ring-enter-guiltypleas/603047002/. [Accessed: 26-Jan-2019].

[51] L. Bellamy, "20 charged in Newburgh drug, prostitution sweep - News - recordonline.com - Middletown, NY," Times Herald-Record, 2018. [Online]. Available: https://www.recordonline.com/news/20181130/20-charged-innewburgh-drug-prostitution-sweep. [Accessed: 26-Jan-2019].

[52] H. de Soto, The mystery of capital: why capitalism triumphs in the West and fails everywhere else. New York: Basic Books, [2000] C2000, 2000.

[53] A. Gilbert, "On the Mystery of Capital and the Myths of Hernando De," Int. Dev. Plan. Rev., vol. 24, no. 1, pp. 1-19, 1990.

[54] R. Florida, "A Better Way To Solve the Global Housing Crisis - CityLab," 2017. [Online]. Available: https://www.citylab.com/equity/2017/07/solving-the-globalhousing-crisis/533592/. [Accessed: 27-Jan-2019].

[55] Reuters, "Brazil Slum Dwellers Shun Home Ownership, Fearing Gentrification," VOANews, 2017. [Online]. Available: https://www.voanews.com/a/rio-slum-favela-homeownership-gentrification/3705588.html. [Accessed: 27-Jan2019]. 
[56] A. Chum, "The impact of gentrification on residential evictions," Urban Geogr., vol. 36, no. 7, pp. 1083-1098, 2015.

[57] N. Carmon, "Three generations of urban renewal policies: analysis and policy implications," Geoforum, vol. 30, no. 2, pp. 145-158, 1999.
[58] C. Murray, "Looking Back," Wilson Q., vol. 8, no. 4, pp. 94$136,1984$. 